\title{
Forceful Orthodontic Extrusion of Maxillary Canine in an Adult Patient: A Case Report
}

\author{
Suruchi Jatol-Tekade ${ }^{1}$ Satyajit Ashok Tekade ${ }^{2} \quad$ Kush Pathak $^{3}$ Vishal Patni ${ }^{4}$
}

\author{
${ }^{1}$ Department of Orthodontics and Dentofacial Orthopedics, Modern \\ Dental College and Research Center, Indore, Madhya Pradesh, India \\ ${ }^{2}$ Department of Oral and Maxillofacial Pathology, Modern Dental \\ College and Research Center, Indore, Madhya Pradesh, India \\ ${ }^{3}$ Department of Oral and Maxillofacial Pathology, Rayat Bahra \\ Dental College, Mohali, Punjab, India \\ ${ }^{4}$ Department of Orthodontics, C.S.M.S.S. Dental College and \\ Hospital, Kanchanwadi, Aurangabad, Maharashtra, India
}

\author{
Address for correspondence Suruchi Jatol-Tekade, BDS, MDS, \\ Department of Orthodontics and Dentofacial Orthopedics, Modern \\ Dental College and Research Center, Gandhi Nagar, Airport Road, \\ Indore, Madhya Pradesh 453112, India \\ (e-mail: suruchitekade@gmail.com).
}

\begin{abstract}
Keywords

- crown lengthening

- fractured tooth

- orthodontic extrusion

Loss of tooth structure in the esthetic region is a big challenge for restorative dentist as it not only involves the establishment of tooth structure but also complies microesthetics. If the tooth structure is lost near the gingival margin, then the periodontal aspect cannot be overlooked. Surgical crown lengthening and orthodontic extrusion of the remaining tooth structure are two possible treatment modalities for such cases. Which one is best suited depends on the indications for each procedure. This study reports an orthodontic extrusion for the restoration of fractured upper canine. Preference of crown lengthening by orthodontic extrusion over surgical crown lengthening is clarified along the case discussion.
\end{abstract}

\section{Introduction}

Tooth structure may be lost because of many reasons. But while performing prosthetic rehabilitation, one must consider the biological width of the involved teeth. Subgingival caries, trauma, subgingival restorations, misplaced restorations, angular defects, and root resorption may hamper the biological width of teeth. To maintain the biological width, 2 to $3 \mathrm{~mm}$ of healthy supracrestal root is necessary. ${ }^{1}$ Maintaining biological width without disturbing the adjacent tooth is a difficult task. Available treatment modalities are extraction, surgical crown lengthening, and orthodontic extrusion of the remaining tooth structure. Extraction followed by prosthetic replacement with bridge or implant are the easiest and commonly followed options. Conversely, every attempt should be made to preserve and conserve the natural tooth structure. ${ }^{2}$ Tooth removal causes ridge deficiency and may need hard or soft tissue augmentation to attain the desired esthetic results. Approving results are hardly possible in vertical ridge augmentation at extraction sites of the esthetic region. They are not time and cost-effective. ${ }^{3}$ Alternative treatment plans may involve more than one specialist including an endodontist, a periodontist, and/or an orthodontist followed by a prosthodontist. Surgical crown lengthening by periodontal procedures removes the supporting supracrestal bone to expose sound tooth structure. ${ }^{4}$ Orthodontic tooth extrusion involves the application of orthodontic traction force to increase clinical crown height by occlusal or incisal movement. ${ }^{5}$ Both procedures prepare adequate coronal tooth structure for suitable restoration. Selection of best-suited treatment modality depends on patients' requirements and indications of the procedure.

When compared with surgical procedure, orthodontic eruption is a conservative approach. It also removes the need for reduction of adjacent teeth for fixed bridge. Extraction of tooth loosens bone or periodontal support. Surgical crown lengthening loosens the crestal bone of the adjacent tooth also. All this can be avoided by simple orthodontic eruption. ${ }^{6}$ Forced orthodontic eruption can be slow and rapid. In slow orthodontic tooth extrusion bone and gingival attachment follows new tooth position. Stronger traction forces from rapid extrusion, cause less coronal migration of the supporting tissues as rapid movement exceeds their physiological limit. ${ }^{6}$ Indications for orthodontic extrusion are subgingival lesion (caries, fracture, perforation, resorption), restorations
DOI https://doi.org/

$10.1055 / \mathrm{s}-0038-1670730$ ISSN 2321-1482.
(C2018 Bhojia Dental College and Hospital affiliated to Himachal Pradesh University
License terms

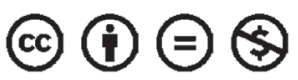


on biological width, angular defects, preimplant extraction, and orthodontic extraction, where surgical extractions are contraindicated. ${ }^{6}$ This case indicates the need for orthodontic extrusion as the restorative area is the esthetic region.

\section{Case Report}

A 48-year-old female patient presented with complaint of fracture of the upper left canine. She had a history of recurring fracture with that tooth. Repeated buildups of an endodontically treated tooth had reduced its clinical crown height ( - Fig. 1a). Now very less tooth structure was available even for core buildup. Therefore, we decided to treat the tooth with crown lengthening. Surgical crown lengthening was not advisable as it would have disturbed the microesthetics of the anterior region. Seeing the overall periodontal condition of canine and adjacent teeth, orthodontic forced eruption was more suitable than surgical crown lengthening. Before starting the treatment, the condition of the patient was evaluated along with periodontal status, smile esthetics, occlusion, and general condition of the dentition. ${ }^{6}$ The patient was convinced for fixed orthodontic treatment in the left upper region. Though the patient needed orthodontic correction of the upper anteriors, she denied full-bonded appliance.

Intraoral periapical radiograph with upper left permanent canine 23 confirmed an intact root canal filling in the root with surrounding normal bone architecture and no subgingival root fracture or periapical pathology. Tooth was prepared for ceramic post. Post and core was built with composite. Stainless steel ligature wire was twisted and formed in a $\mathbf{U}$ shape and then cemented into the canal with flowable composite ( - Fig. 1b). Anchoring teeth 24 and 25 were bonded with $0.022^{\prime \prime}$ orthodontic brackets. The $0.019 \times 0.025^{\prime \prime}$ straight length TMA (titanium molebdenum alloy) wire was engaged in it before bonding to reduce undue leveling aligning forces on the anchoring teeth. This wire was then removed from the slot and formed into a spring that came occlusally downward and bent horizontally toward the

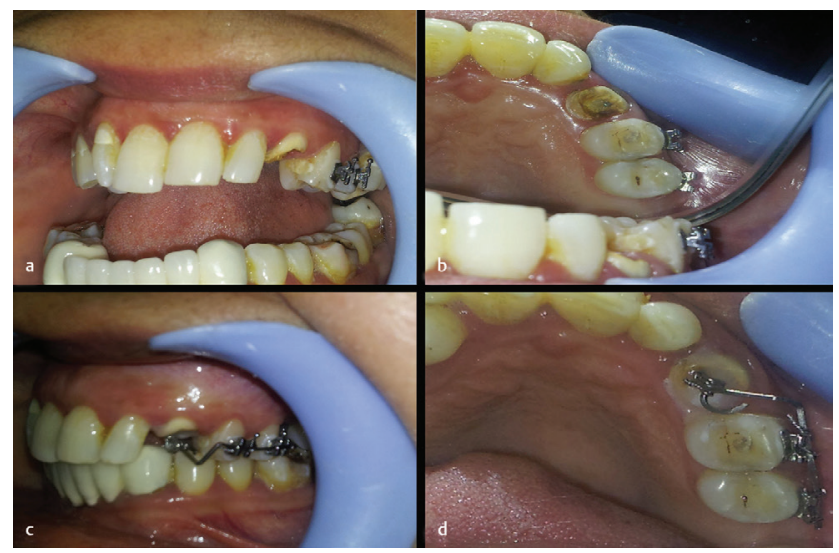

Fig. 1 (a) Decreased clinical crown height of 23. (b) Stainless steel ligature wire was twisted and formed in a $\mathbf{U}$ shape, and then cemented into the canal with flowable composite. (c) $0.019 \times 0.025$ TMA wire formed in spring and engaged in 23, 24, and 25 to give downward pull to 23. (d) Anterior end of spring engaged in a $\mathbf{U}$-shaped pin cemented in 23. tooth. Its end was turned forming a loop. Straight part of this TMA wire was engaged in 24 and 25 brackets, and the anterior end was tied with a ligature wire hanging from the

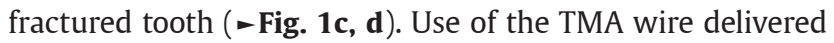
light continuous force enabling coronal migration of the attachment apparatus. ${ }^{3}$ Activation of extrusion force was performed by twisting ligature wire. Total extrusion of 2 $\mathrm{mm}$ was achieved within a span of 2 months. Wires were kept fixed for another month for stabilization. The achieved coronal length of the extruded tooth was assessed for its adequacy to retain full coverage restoration, and then the ceramic crown was cemented on it. The patient was advised to wait for 6 months to see stable and asymptomatic results (-Fig. 2a-c).

\section{Discussion}

The idea of maintaining the biological width of the periodontium is important for healthy periodontal tissue. ${ }^{1}$ Destruction of biological width results in inflammation and bone resorption. Clinically, it may present as gingival recession or pocket formation. ${ }^{7}$ Subgingival extension of caries, restorations or fracture line creates restorative problems and affected teeth routinely get extracted than alternative multidisciplinary approach. The use of orthodontic force for crown lengthening ${ }^{5}$ than periodontal crown lengthening can promise more esthetic and retainable results.

Heithersay and Ingber first described orthodontic extrusion for crown lengthening. The technique uses principles of osteophysiology and orthodontics. Application of light orthodontic force creates tension on periodontal fibers, causes their elongation, and results in osteoinduction through osteoblasts. Osteoblasts deposit new bone following the alveolar bone where periodontal fibers are attached. This results in coronal movement of the bone with extrusion of the tooth. This procedure can correct infrabony pockets, repositioning gingival margin and clinical crown lengthening. ${ }^{5}$

There are different techniques in the literature to carry out forced eruption of teeth orthodontically. An orthodontic force of 15 to $30 \mathrm{gm}$ is needed for slow orthodontic extrusion, ${ }^{8,9}$ whereas forces above $50 \mathrm{gm}$ can bring about rapid tooth extrusion. ${ }^{10}$

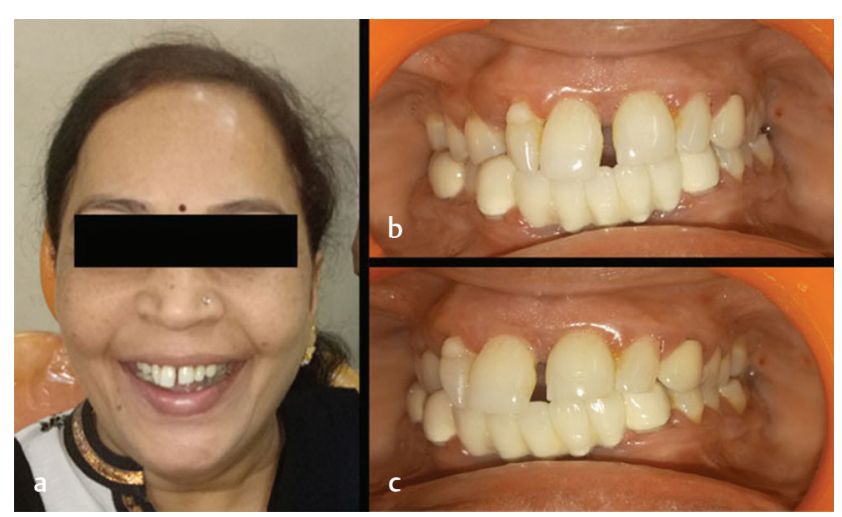

Fig. 2 (a) Posttreatment front facial photograph of the patient. $(\mathbf{b}, \mathbf{c})$ The achieved coronal length of the extruded tooth was used to retain full coverage restoration and then ceramic crown was cemented on 23. 
Ulusoy ${ }^{11}$ and Fidel et a ${ }^{12}$ performed extrusion by bonding brackets on the adjacent teeth. But bonding adjacent teeth may consume time for leveling and aligning. Murali et al suggested the use of lingual self ligating brackets for extrusion. ${ }^{13}$ Though the technique in this case report uses straight length TMA wire, clinician intentionally removed aligning phase by bonding brackets along the straight wire to make them passive. Heda et a $\mathrm{l}^{14}$ and Patil et $\mathrm{al}^{15}$ suggested the use of bonded stainless steel wire to the adjacent teeth. Patil et al gave vertical steps to enhance the extrusion force. There are techniques using springs on banded appliance and springs with removable Hawley's appliance. ${ }^{6}$ Bondemark et al suggested the use of magnets for extrusion of root stump. ${ }^{10}$ Forceps eruption method described by Argueta et a ${ }^{16}$ may cause inflammation and pain in an already compromised tooth structure. Orthodontic extrusion by any orthodontic technique is better than surgical intervention. It is a conservative procedure that prevents undue reduction of healthy tooth structure as required in fixed bridge preparation. Extraction causes loss of bone and periodontal support. Even surgical crown lengthening causes some amount of bone loss of the teeth adjacent to the tooth that needs to be extruded. Therefore, comparing all aspects, orthodontic extrusion is a simple technique which easily brings about tooth movement. ${ }^{6}$ Current concepts are avoiding treatment options which create compromised esthetics and maintain long-term stability of the results. ${ }^{17}$ Clinical crown lengthening is nothing but increasing supragingival tooth structure for esthetic or restorative purpose. Therefore, rather than extracting the compromised tooth and replacing it with fixed bridge or costly implant, crown lengthening should be tried as a possible treatment option. Singh and Verma further suggested the use of orthodontic eruption followed by periodontal surgery to enhance microesthetics than surgery alone. ${ }^{4}$

\section{Conclusion}

Endodontic-orthodontic-prosthodontic-periodontic cotreatment is necessary for cases with complex clinical condition. Without a multidisciplinary approach, one cannot make a compromised tooth fit to attain fixed prosthesis which is sound functionally and esthetically. Despite the fact that orthodontic tooth eruption seems to be a time-taking treatment modality, its ease of application and cost-benefit effect make it acceptable by general practitioners and even by patients.

\section{Conflict of Interest}

None.

\section{References}

1 Shenoy A, Shenoy N, Babannavar R. Periodontal considerations determining the design and location of margins in restorative dentistry. J Interdiscip Dentistry 2012;2:3-10

2 Tekade SS, Khatri JM, Tekade SA, Pathak K. Can we stop 3rd molar abortions? J Res Adv Dent 2015;4(3):19-22

3 Shyammohan A. Forced eruption: an adjunct to prosthodontic treatment planning. Indian J Stomatol. 2011;2(4):260-262

4 Singh A, Verma R. Crown lengthening vs forced eruption. Orthod J Nepal 2011; 1(1):52-55

5 Johnson GK, Sivers JE. Forced eruption in crown-lengthening procedures. J Prosthet Dent 1986;56(4):424-427

6 Bach N, Baylard JF, Voyer R. Orthodontic extrusion: periodontal considerations and applications.J Can Dent Assoc 2004;70(11): 775-780

7 Magne P, So WS. Optical integration of incisoproximal restorations using the natural layering concept. Quintessence Int 2008;39(8):633-643

8 Minsk L. Orthodontic tooth extrusion as an adjunct to periodontal therapy. Compend Contin Educ Dent 2000;21(9): 768-770, 772, 774 passim

9 Reitan K. Clinical and histologic observations on tooth movement during and after orthodontic treatment. Am J Orthod 1967;53(10):721-745

10 Bondemark L, Kurol J, Hallonsten AL, Andreasen JO. Attractive magnets for orthodontic extrusion of crown-root fractured teeth. Am J Orthod Dentofacial Orthop 1997;112(2):187-193

11 Ulusoy A. Indirect composite restoration of a crown fracture. ASDC J Dent Child 2012;79:2

12 Fidel SR, Fidel-Junior RA, Sassone LM, Murad CF, Fidel RA. Clinical management of a complicated crown-root fracture: a case report. Braz Dent J 2011;22(3):258-262

13 Murali RV, Rajashekhar L, Rajalingam S. Extrusion of fractured anterior tooth - an invisible approach. Indian J Multidiscip Dent 2011;1(2):96-99

14 Heda CB, Heda AA, Kulkarni SS. A multi-disciplinary approach in the management of a traumatized tooth with complicated crown-root fracture: a case report. J Indian Soc Pedod Prev Dent 2006;24(4):197-200

15 Patil SS, Panicker AS, Hindlekar A, Srinidhi SR, Dhumal A, Vhora K. Forced orthodontic extrusion for anterior traumatized teeth by a simplistic approach. J Dent Allied Sci 2014;3:111-113

16 Argueta J, Orellana A, Plotinoc G. Surgical extrusion: a reliable technique for saving compromised teeth. A 5-years follow- up case report [in Italian]. G Ital Endod 2018;32(1):25-30

17 The American Academy of Periodontology. Glossary of periodontal terms, American Academy of Periodontology. 4th ed. Chicago (2001) 